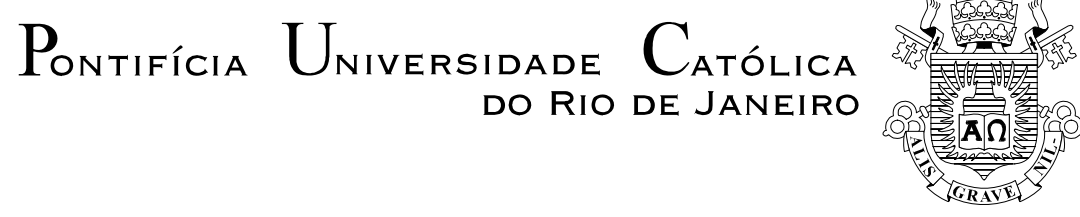

Orlando Carlos Neves Belém

\title{
Do Foro Privilegiado à Prerrogativa de Função
}

Dissertação de Mestrado

Dissertação apresentada ao Programa de Pós-graduação em Direito da PUC-Rio como requisito parcial para obtenção do título de Mestre em Direito.

Orientadora: Profa Ana Lúcia de Lyra Tavares

Rio de Janeiro

julho de 2008. 


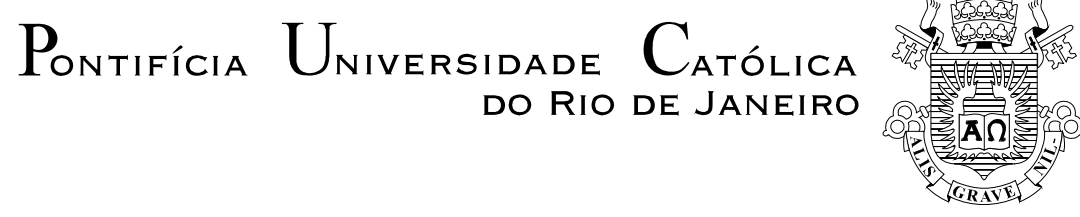

Orlando Carlos Neves Belém

\title{
Do Foro Privilegiado à Prerrogativa de Função
}

\author{
Dissertação apresentada ao Programa \\ de Pós-Graduação em Direito da PUC- \\ Rio como requisito parcial para \\ obtenção do título de Mestre em Direito. \\ Aprovada pela comissão examinadora \\ abaixo assinada.
}

Profa . Ana Lúcia de Lyra Tavares Orientadora Departamento de Direito - PUC-RJ

Prof. Francisco Mauro Dias Departamento de Direito - PUC-RJ

Prof. Humberto Dalla Bernardina de Pinho Departamento de Direito - UERJ

Prof. Nizar Messari Vice-Decano de Pós-Graduação do Centro de Ciências Sociais - PUC-Rio

Rio de Janeiro, 03 de julho de 2008. 
Pontifícia Universidade Católica $_{\text {a }}$

DO RIO DE JANEIRO

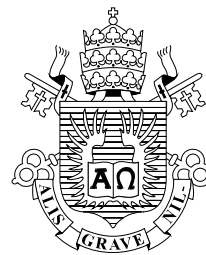

Todos os direitos reservados. É proibida a reprodução total ou parcial do trabalho sem autorização da Universidade, da autora e da orientadora.

\title{
Orlando Carlos Neves Belém
}

Graduou-se em Bacharel em Direito no ano de 1987 pela Universidade Federal do Rio de Janeiro e ingressou no Ministério Público do Estado do Rio de Janeiro no ano de 1991, no cargo de Promotor de Justiça. Procurador de Justiça desde 2007. Foi Professor de Direito Constitucional na Sociedade de Ensino Superior Estácio de Sá, na Escola da Magistratura do Estado do Rio de Janeiro - EMERJ, na Fundação Escola do Ministério Público FEMPERJ e no Curso Glioche.

Ficha Catalográfica

\author{
Belém, Orlando Carlos Neves. \\ - Do Privilegiado à Prerrogativa de Função / Orlando \\ Carlos Neves Belém; orientadora: Ana Lúcia de Lyra \\ Tavares. - Rio de Janeiro: PUC, Departamento de Direito, \\ 2008. \\ $166 \mathrm{fls} .29 \mathrm{~cm}$ \\ Dissertação (mestrado) - Pontifícia Universidade \\ Católica do Rio de Janeiro, Departamento de Direito. \\ Inclui referências bibliográficas.
}

1. Direito - Teses. 2. Privilégio. 3. prerrogativa de função. 4. Princípio Republicano. 5. auto-organização. 6. competência originária. I. Tavares, Ana Lúcia de Lyra, II. Pontifícia Universidade Católica do Rio de Janeiro. Departamento de Direito. III. Título. 


\section{Agradecimentos}

A minha orientadora, Professora Ana Lúcia de Lyra Tavares, o meu testemunho é representado pela gratidão infinda da ajuda prestada e do saber partilhado. Muito obrigado!

A todos os Professores integrantes do Programa de Pós-Graduação em Direito da PUC-Rio, pela troca incessante de informações, o incentivo e a dedicação à frente deste nobre ofício de divulgar idéias e pensamentos. Um destaque aos Professores Adrian Sgarbi, Francisco Mauro Dias, Gustavo Senèchal de Goffredo e José Ribas Vieira, porquanto, cada um, de um modo singular, contribuiu bastante para esta jornada.

À Pontifícia Universidade Católica do Rio de Janeiro pelo auxílio indispensável e efetivo.

Aos queridos e prestimosos Anderson e Carmen, considerando a ajuda prestada pelos mesmos.

A Juliana de Lima Brandão pela paciência e ajuda diária na digitação deste texto. Serei sempre grato!

A Maria Amélia Couto Carvalho, Denise Freitas Fabião Guasque e a Lázaro José Freitas Calvino por trocarem impressões sobre o assunto e pela amizade.

Aos meus Pais, simplesmente, pela Vida que me proporcionaram. E, eternamente, pelo carinho e amor devotados.

A Eliane (Naninha) por ser tudo para mim. Você me completa e como diz a canção: “siempre está en mi corazón”. 


\section{Resumo}

Belém, Orlando Carlos Neves; Tavares, Ana Lúcia de Lyra. Do Foro Privilegiado à Prerrogativa de Função. Rio de Janeiro, 2008. 166 p. Dissertação de Mestrado - Departamento de Direito. Pontifícia Universidade Católica do Rio de Janeiro.

O privilégio desde a Antiguidade, quase sempre, esteve associado à função judicante e, acima de tudo, legitimado sob o ponto de vista legislativo. Na verdade, muitos foram os conflitos gerados pelas tentativas de manutenção ou de extinção dos privilégios conferidos aos membros da Igreja e aos nobres. É sustentável a afirmação de que o privilégio, por um lado, conheceu uma forte restrição nos países orientados pela Common Law, um traço marcante desde a Carta Magna de 1215, diferentemente do contexto em que se formou na Península Ibérica, onde o mesmo, frequentemente, teve o seu embasamento normativo autorizado nas Leis das Siete Partidas e nas Ordenações, inclusive, durante o período da inquisição. A organização política daquela época, a rigor, foi baseada em um sistema complexo das relações feudais, no caso, desconhecedora da igualdade entre os membros do mesmo grupo social e que propiciava uma patente superioridade do nobre e das pessoas associadas às funções mais importantes do Reino. Evidentemente, em virtude do prolongamento destas situações de desigualdade, o advento da Declaração de Direitos de Virgínia de 1776 consolidado com a emissão da Declaração dos Direitos do Homem e do Cidadão da Revolução Francesa de 1789 exerceu, cada qual, uma forte contribuição para a eliminação de toda a gama de privilégios existentes na esfera da sociedade, a par de proclamar a idéia de valorização do ser humano sem retrocessos, Embora o privilégio não guarde equivalência com a prerrogativa de função, não se pode chegar ao exame do mesmo, sem antes pesquisar a sua tradição normativa, ou seja, o sistema do qual fazia parte. Portanto, a paulatina rejeição dos privilégios nos países influenciados pela Common Law resultou, nos dias atuais, na inexistência do foro por prerrogativa de função, enquanto a natural leniência dos países da Península Ibérica com a sua existência e aceitação, ao seu turno, deu ensejo a um complexo padrão normativo, o qual se notabiliza pelo estabelecimento do foro por prerrogativa de função em moldes exagerados e desvirtuadores dos princípios formulados na Revolução Francesa e com o surgimento das Constituições liberais. Seguimos com a análise e o desenvolvimento do foro por prerrogativa de função no Brasil, para tanto tomando como amparo as fontes normativas portuguesas e, ainda, a influência constitucional americana, principalmente por ocasião da adoção do Princípio Republicano entre 1889 a 1891, bem como as distorções causadas pela sua extensão aos cargos públicos de menor importância na República brasileira e a impossibilidade por demais evidente, de sua ampliação às causas cíveis fornecem elementos concretos do caráter dinâmico do tema e das alternativas criadas em cada constitucionalismo para inseri-lo nos respectivos domínios normativos.

\section{Palavras-chave}

Privilégio; prerrogativa de função; Princípio Republicano; autoorganização; competência originária. 


\section{Résumé}

Belém, Orlando Carlos Neves; Tavares, Ana Lúcia de Lyra. De privilège à la prérogative attachées à certains fonctions. Rio de Janeiro, 2008. 166 p. Mémoire de Maîtrise. Département de Droit. Université Pontificale de Rio de Janeiro.

Dès l'Antiquité, le privilège de juridiction a presque toujours été associé à la fonction judiciaire et surtout considéré légitime au point de vue législatif. A vrai dire, les essais ayant en vue soit le maintien soit la supression des privilèges octroyés aussi bien aux membres de l'Eglise qu'aux nobles ont déclenché de nombreux conflits. Il est possible d'affirmer que le privilège de juridiction était conçu de façon restrictive dans le pays issus du système de la Common Law, notamment à partir de la Charte de 1215, différemment de ce qui se passa dans la Péninsule Ibérique où les fondements normatifs du privilège étaient fournis par les Lois des Siete Partidas et par Ordonnances, y compris pendant l'Inquisition. L’organisation politique de cette époque-la était bâtie à partir d'un système complexe de rapports féodaux. D'une part, elle méconnaissait l'égalité qui devrait exister entre les membres du même groupe social et d'autre part elle favorisait une nette supériorité des nobles ainsi que des personnes associées aux fonctions les plus hautes du Royaume. Certes, en raison de la durée de ce cadre inégalitaire, la Déclaration des Droits de Virginie de 1776, la Révolution Française de 1789 et la Déclaration de Droits de l'Homme et du Citoyen de la même année ont joué um rôle décisif pour l'abolition de toutes sortes de privilèges existant dans la societé en proclamant en outre l`idée de la mise en valeur de la personne humaine à être poursuivie de façon irréversible. Quoique le privilège de juridiction n`équivaut pas à la prérogative de fonction, on ne peut pas l'étudier sans entreprendre d'abord l'examen de sa tradition juridique, c'est à dire, du système de droit auquel il appartenait. On peut donc constater que le rejet graduel des privilèges dans le pays appartenant au système de la Common Law a fait que de nos jours inexiste dans ces pays le privilège de juridiction tandis qu'une situation distincte se dégage dans le pays ibériques. Dans ceux-ci, la tolérance à l’égard des privilèges a créé un cadre normatif complexe dans lequel le privilège de juridiction est reconnu de façon exagérée, défigurant la notion même d’égalité proclamée par la Révolution Française et reprise par les Constitutios de la démocratie liberalé. Après avoir remonté aux racines générales du sujet, nous avons poursuivi notre étude en examinant la prérogative de fonction au Brésil à partir des sources normatives portugaises, en passant par l'influence constitutionnelle du droit américan, notamment lors de l'adoption du principe républicain, entre 1889 et 1891 . Nous nous penchons également sur les distorsions entraînées par l’octroi de ce privilège, dans notre République, à certaines fonctions d`importance mineure. De même, nous examinons l'impossibilité de l'étendre aux affaires civiles. Ces aspects, entre autres, traduisente la nature dynamique du thème et les voies distinctes de son traitement au niveau des systèmes constitutionnels.

\section{Mots-clés:}

Privilège de juridiction, prérogative de fonciont; príncipe républicain; autoorganisation; compétence juridictionnelle en premier ressort. 


\section{Sumário}

1.Introdução 10

$\begin{array}{ll}1.1 \text { Objetivo da dissertação } & 10\end{array}$

1.2. Plano de exposição e justificação 12

$\begin{array}{ll}\text { 1.3. Método } & 17\end{array}$

2. Retrospectiva e considerações sobre o privilégio na história

2.1. Grécia: Privilégio no âmbito da justiça e dos cidadãos, Roma: O privilégio e a sua inclusão na vida política (esfera pública) e os Hebreus: O privilégio correlacionado aos intérpretes das Escrituras Sagradas

2.2. O Privilégio no Período da Civilização Ocidental Medieval e Moderna

2.2.1. O Período Bizantino e a influência do modelo Romano quanto ao privilégio

2.2.2. Abordagem dos privilégios dos clérigos na Europa e os embates mantidos entre a Igreja e os monarcas

2.2.2.1. Constituições de Clarendon. Conflitos entre a Igreja e o monarca pela manutenção dos privilégios. Caso Thomas Becket versus o monarca Inglês Henrique II. A extinção dos privilégios da Igreja Católica Apostólica Romana na Inglaterra e outros países da Europa

2.2.3. Exame do Privilégio na Espanha, Portugal e no Brasil Colônia

2.2.3.1. Exame dos privilégios na Lei das Siete Partidas e nas Ordenações

2.2.4. Privilégio dos agentes encarregados da Inquisição (Séculos XV-XIX)

2.3. A contestação dos privilégios no constitucionalismo americano e a herança política de Locke

2.4. Privilégios estabelecidos na corte francesa. A Revolução

Francesa, um momento histórico destinado à eliminação dos privilégios da sociedade de corte francesa

3. Análise comparativa do foro por prerrogativa de função

3.1. A competência originária dos Tribunais nos Estados Unidos e na Inglaterra. Países orientados pela Common Law

3.2. Foro por prerrogativa de função nos Países Ibéricos e a estrutura dos Tribunais dotados de competência originária. Assunto reservado à legislação infraconstitucional

3.3. Análise no plano Constitucional do Foro por prerrogativa de função na Europa Ocidental. França e a criação da Corte de Justiça da República. Alemanha e a competência da Corte Constitucional 
4. A cultura do privilégio no Brasil

108

4.1. Análise dos Privilégios concedidos pela Coroa Portuguesa aos Ingleses em território Português e no Brasil Colônia. Atuação da Inglaterra na garantia de benesses aos súditos ingleses

4.2. Constituição do Império de 1824 , a instituição do Poder Moderador, a abolição dos privilégios puramente pessoais e a instituição dos privilégios de causa ou de foro. A manutenção dos privilégios aos membros da Igreja no Decreto 609, de $18 / 08 / 1851$

4.3. Instituição da República no Brasil e o foro por prerrogativa de função

4.4. Evolução do foro por prerrogativa de função na Constituição Federal de 1946 e nas Constituições Estaduais promulgadas na vigência da mesma Carta Política. Coronelismo uma forma representativa do exercício de um privilégio odioso

4.5. Foro por prerrogativa de função na vigência da Constituição de 1967 (EC n. 1 de 17-10-69) e o Ato Institucional n. 5, de 18 de dezembro de 1968

4.6. Foro por prerrogativa de função na Constituição de 1988: a inadmissibilidade da manutenção do julgamento às autoridades não mais detentoras de cargo público e a impossibilidade de extensão do foro por prerrogativa às ações de improbidade da Lei n. 8.429/92

4.6.1. Foro por prerrogativa de função no plano municipal

4.6.2. Foro por prerrogativa de função e o exame na esfera da Justiça Eleitoral

4.6.3. A competência originária do Superior Tribunal Militar

4.6.4. A autonomia dos Estados Federados e o foro por prerrogativa de função

4.6.5. Crítica ao foro por prerrogativa de função anteriormente definido em Medidas Provisórias

5.Conclusões 


\section{Lista de abreviaturas:}

ADC - Ação Declaratória de Constitucionalidade

ADCT - Ato das Disposições Constitucionais Transitórias

ADI - Ação Direta de Inconstitucionalidade

ADIn - Ação Direta de Inconstitucionalidade

C. de Cádiz - Constituição de Cádiz de 1812

C. do Imp. - Constituição do Império de 1824

CE - Constituição Espanhola

CERJ - Constituição do Estado do Rio de Janeiro

CF - Constituição Federal

CFr - Constituição Francesa

CClar. - Constituições de Clarendon

CP - Constituição Portuguesa

CPPB - Código de Processo Penal Brasileiro

CPPP - Código de Processo Penal Português

CRFB - Constituição da República Federativa do Brasil

DJ - Diário de Justiça

EC - Emenda Constitucional

HC - Habeas Corpus

INQ. - Inquérito

MC - Medida Cautelar

QO - Questão Originária

STJ - Superior Tribunal de Justiça

STF - Supremo Tribunal Federal

STM - Superior Tribunal Militar

TJRJ - Tribunal de Justiça do Estado do Rio de Janeiro

TRE - Tribunal Regional Eleitoral

TRF - Tribunal Regional Federal

TSE - Tribunal Superior Eleitoral 